\title{
Renascence of Urban Industrial Heritages on the Background of Creative Industry Development
}

\author{
Yanan Yang \\ Huanghe Science and Technology College \\ Zhengzhou, China 450046
}

\begin{abstract}
From 2004 till now, China's authorities have implemented a series of policies and development planning in regard to the cultural creative industry and the country has gradually entered a stage where the tertiary industry has become a backbone for the economic development. Along with the economic transformation, there is a batch of original spaces (as industrial buildings and plants etc) for industrial production needing to be transformed with the economic development. During this transformation, a good many of industrial heritages will be directly destroyed and replaced by business centers or commercial houses. Seen from the essence of spatial economic development, there is a kind of new transformation pattern on the background of cultural creative industry, which is the value transformation of industrial heritages, that is, to achieve the "renascence" of the industrial heritages. This article makes a discussion from three aspects for the "renascence" of the industrial heritages, namely functions, forms and spatial productivity. Also through the analysis on the "renascence" of original industrial heritages in domestic creative industrial areas, and the article provides favorable reference patterns for the transformation of industrial heritages in the creative industrial areas of other regions.
\end{abstract}

Keywords-creative industry; industrial heritages; spatial productivity

\section{INTRODUCTION}

The cultural creative industry has witnessed the development over a decade in China and has become an important part of GDP and a backbone for the tertiary industry. The Eighteenth National Congress of the Communist Party of China put forward a strategic decision of rapid development of cultural creative industry and construction of a country powerful in culture. And the researches on the urban cultural creative industry will have important practical significances on promoting the upgrade and transformation of urban industries and pushing the urban sustainable development. After entering the 21 st century, as an output of the deep integration of culture, technology and economy, the cultural creative industry, relying on the unique industrial value chain, rapid growth mode and broad industrial penetration, influence and radiation has become a new highlight of global economy and modern industrial development as well as a new drive for the economic development of the country ${ }^{[1]}$.

On the background of prosperity and development of the cultural creative industry across the country, this article concludes and collates the development of industrial buildings in the creative industry parks, raising solutions for the "renascence" of the industrial buildings. Through the design and analysis of the "renascence" in three aspects of the industrial buildings and taking cases of "renascence" of the industrial buildings in the creative industry parks in some areas at home to analyze the selection of the time---"renascence" of industrial buildings on the background of creative industry..

\section{OVERVIEW OF CREATIVE INDUSTRY}

In 1998, the British government issued a Creative Industries Mapping Document which was the first to raise the concept of "Creative Industries", and actively promoted the development of the creative industries. Hawkins, a culture economist,, defined the creative industries from the perspective of intellectual property in his works Creative Economy as: an economic department with its products all within the protection of Intellectual Property Laws. The intellectual properties consist of four categories: patents, copyright, brands and design. Hawkins thought that each form of the Intellectual Property Laws has enormous industry to correspond with and added together, "the four industries will constitute the creative industries and creative economy" [2]. The United Nations Conference on Trade and Development (UNCTAD) defined the cultural creative industries as: "the creative cycle takes the creative and intellectual capital as the initial investment in products and services and makes profits through trade and intellectual property..." ${ }^{[3]}$.

In those years of the creative industry development, the researches of massive scholars show that most of the agglomeration locations for cultural creative industries are in the abandoned industrial areas in metropolitans. After the traditional manufacturing industry in the western industrial metropolis declined, many abandoned plants were left. Mommaas (2009) thought that the agglomeration of cultural creative industries not only have the construction of cultural infrastructures in new forms but also reconstruct and reuse the abandoned plants and warehouses ${ }^{[4]}$. Under the overall background of creative industries, many domestic industrial building spaces need not be destroyed but be directly reused or reconstructed to give them a "renascence".

Program Category: Zhengzhou Soft Science Research Program, Program No.: 141 prkxf612. 
III. THE DEVELOPMENT OF INDUSTRIAL HERITAGES IN OUR COUNTRY

\section{A. Sttatus quo of Industrial Heritages}

The lack of scientific and reasonable guidance in early domestic development planning has resulted in a series of follow-up problems on the transformation from the industrial development period to the modern economy in our country. The currently emerging problems of a lot of unused and abandoned old industrial buildings in our country have close relations with the current urban construction and the economic system transformation. Due to the messy distribution, high proportion of land occupation, occupying the preponderant locations as well as serious environment pollution etc, the early domestic industrial building areas have become one of the major subjects to be transformed ${ }^{[5]}$. Starting from the 1990 s, the increasingly rapid development of urban construction has promoted the urban industrial structure to be adjusted from the secondary industry to the tertiary industry; the transformation of land use system from planned allocation and uncompensated use to paid use caused the adjustment of land-use structure; the urban industrial system adopts the development strategy of "shifting from labor-intensive industry to service economy", the industrial enterprises in the urban center (the secondary industry) are migrated to the suburbs while the left spaces are used for the development of the tertiary industry; industrial centers shift to the emerging industrial areas and so on, all of these have accelerated the appearance of abandoned and unused old industrial buildings [6]. Because our country has not paid enough attentions to the protection of industrial heritages, the $30^{\text {th }}$ UNESCO World Heritage Center conference held in the Republic of Lithuania in July 2006 published 32 items of world heritage list possessed by our country, thereinto, there was only 1 item of industrial heritage - the Dujiangyan Irrigation System at Qingcheng Mountain, compared with European countries, there is a still large distance (table 1$){ }^{[7]}$

TABLE I. COMPARISON BETWEEN THE QUANTITY OF CHINESE INDUSTRIAL HERITAGES AND THAT OF OTHER COUNTRIES

\begin{tabular}{|l|l|l|l|}
\hline Countries & \multicolumn{1}{|c|}{$\begin{array}{c}\text { Quantity of } \\
\text { world heritages }\end{array}$} & $\begin{array}{c}\text { Quantity of } \\
\text { industrial } \\
\text { heritages }\end{array}$ & $\begin{array}{c}\text { Proportion of } \\
\text { industrial } \\
\text { heritages }\end{array}$ \\
\hline China & 32 & 1 & 3.13 \\
\hline Britain & $25+0.5$ & 6 & 25.53 \\
\hline Germany & $29+0.5+0.5$ & 3 & 10 \\
\hline Belgium & $8+0.5$ & 3 & 35.29 \\
\hline Sweden & $13+0.1$ & 3 & 22.9 \\
\hline France & $28+0.5+0.5$ & 3 & 10.34 \\
\hline
\end{tabular}

There are problems in Chinese industrial heritages such as unclear protection concept, undefined system and lack of management etc. On the one hand, the urbanization process makes it scare for the urban construction land use. During the renewal of industrial land, demolishing all the industrial remains is the easiest method so there is no time to consider the "industrial heritage protection". On the other hand, the people have a weak protective consciousness for heritages unwilling to financially invest protection of the dirty, ugly and contaminative industrial facilities ${ }^{[8]}$. Although the overall situation is so severe, after the Seventeenth and Eighteenth
Congress of the CPC, relying on the policy promotion for cultural creative industries, the industrial heritages begin to restore overall and develop sustainably.

\section{B. The Renewal Pattern of National Industrial Heritages}

China has gone through nearly a decade of development of cultural creative industries, thereinto, the transformation and reuse of industrial buildings has begun to take shape and formed a mainstream pattern of industrial building transformation which mainly have the following patterns: (1). transform the industrial buildings into art studios, art galleries, art shops and exhibition rooms etc; (2). transform the industrial buildings into coffee houses, convenience stores and bookstores etc; (3). transform the industrial buildings into design companies and network technology companies etc. The three mainstream patterns mentioned above have multiple forms but the essence is relatively single, focusing on office and leisure and lack of more broad creativity, the patterns are suitable for the small-scale industrial building groups but are difficult to bear the large-scale industrial buildings. At the same time, in the mainstream patterns, the projects using the original industrial lands for the real estate development also appear such as Vanke Tianjin Crystal City, thus the urban industrial heritages achieve the "renascence" on the basis of industrial heritages.

In 2003, Vanke Real Estate promoted a large-scale residential community with high quality- the Crystal City, located in the south of Tianjin, which was the site of the former Tianjin Glassworks. This is the first domestic largescale residential community which reserves historical sites of the industrial age. The Crystal City possesses abundant vegetation and cultural resources with 600 large trees, old plants, hoisting workshops, dispatching rails and chimneys and other industrial heritages. Generally speaking, these are all obstacles for the land development of developers and usually are destroyed. While the development of this land by Vanke tried to maintain the historical styles and features of original industrial buildings and skillfully integrate it to new buildings and maintain the avenues and gardens of original industrial plant areas in the new planning from the perspective of protecting, developing and recycling of industrial heritages; the hoisting workshops adopt modern materials and new forms for display and rebuild the industrial buildings in this area into translucent community clubs; maintain the original railways and water towers in the plant areas as important landscapes in the landscape planning of residential district (as shown in Fig. 1 and Fig. 2). We can see from the real map in this case that this project conducted selective protection to the original old plant areas which mainly aims at the main buildings (such as industrial workshops, warehouses and residential areas etc) and partly adopted the road planning of original industrial areas with the purpose of maintaining the existing ecological environment for recycling and costs reduction along with the guarantee of the integrated environment. 


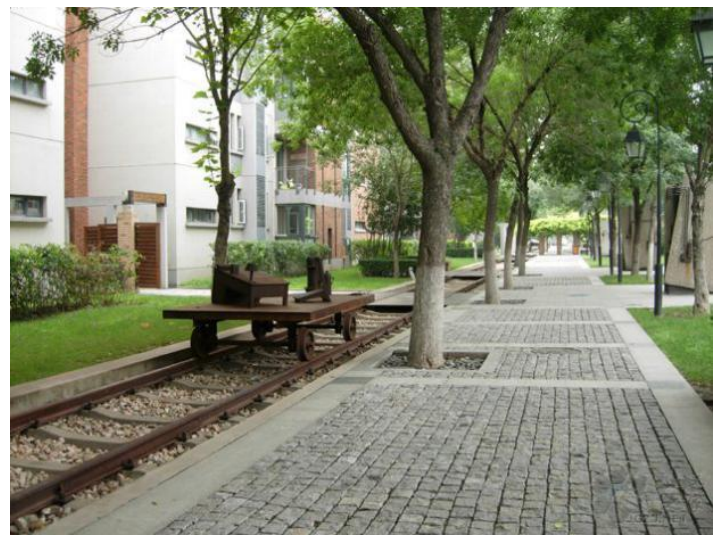

Fig. 1. Railway landscape of industrial area in residential area

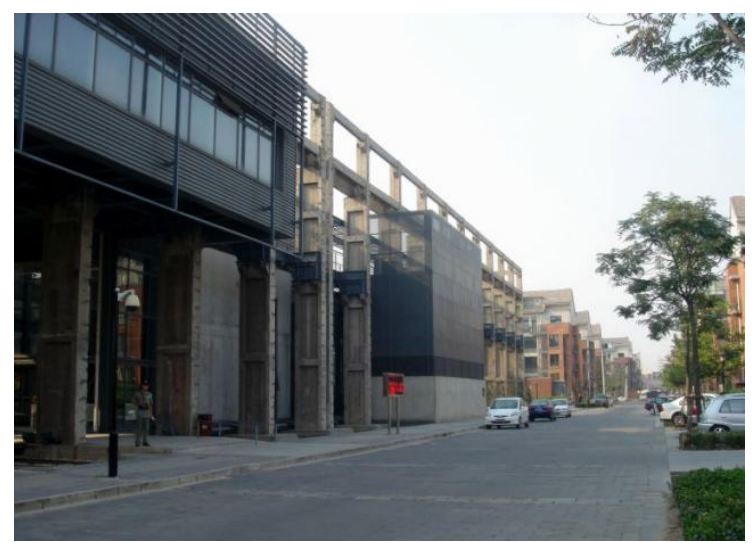

Fig. 2. The owner's club in residential area by reconstruction of old workshops

\section{INDUSTRIAL HERITAGES RENASCENCE UNDER THE BACKGROUND OF CREATIVE INDUSTRY}

\section{A. How the Creative Industry Drives the "Renascence" of Industrial Heritages}

The creative industry is an effective prescription for the sustainable economic development. During the period of national economic transition and the transitional period from the secondary industry to the tertiary industry, the secondary industry is in transformation and upgrading and the original industrial model of extensive pattern has been outdated. Most of the industrial buildings left will still remain which will cause a large number of problems such as the land occupation of industrial building groups and management and maintenance of industrial building groups etc. Under this situation, the development mode we can adopt is to conduct selective protection and selective development to the original industrial buildings and conduct the layered development to industrial buildings: conduct key protection with a little of maintenance development to those belonging to the industrial heritages; conduct selective protection and integrated development and reconstruction to those belonging to common industrial buildings (including transformation and reinforcement of buildings and the integrated layout transformation of building groups etc); conduct the protective dismantlement to those belonging to the waste and dangerous industrial buildings; after the development of the first part, relocate its region and conduct development and relocation to this part. The overall development is divided into two major kinds: (1). the development mode dominated by economic interest; (2). the public interest development mode dominated by the protection of urban industrial heritages and the propaganda (with small quantity of economic interest).

To achieve the actual development of the two aspects, the following three preconditions will be needed:

1) Spatial resource allocation of industrial buildings: Aiming at the overall development environment of industrial buildings, conduct the re-layout and break the resource allocation of original industrial groups and the distribution of functional areas. Conduct the predictive layout according to the external environment of buildings within the current or future periods. And conduct new space system resource allocation according to the industrial distribution around the buildings, classifications of residents and regional economic capacity, etc.

2) Industrial buildings are a group memory during the urban development: The industrial building development must be conducted with the investigation and interview of policies on the residents in original residential areas and the reasonable suggestions of original residents must be taken which shall be applied in the planning layout. An the important reason for the mode is because the urban building environment is a basic urban image formed by the people in the environment, and a memory of the people on the development of the city and a mode for urban culture inheritance and development.

3) Promotion of national policies and application of innovative thinking: In China, except for the factors of capital market, the most important factor for promoting the economic development is the policy environment. In the regional economic development, the policy is a powerful impetus. Therefore, we should reasonably understand and apply the current relevant state policies. With the support of current made in China 2025, rapid development of cultural creative industries and promotion of national innovation ability and so on, we should even analyze the impetus of policies on the "renascence" of industrial buildings so as to proceed with the layered development of industrial buildings.

\section{B. “Renascence" of Industrial Buildings}

In the term of the essence of spatial economic development, there is a new transformation pattern under the cultural creative industries which is a value transformation of industrial heritages, that is, to grant a "renascence" to the industrial heritages. This paper discusses from three aspects of "renascence" of industrial heritages, namely functions, forms and spatial productivity.

1) The functional "renascence" of industrial buildings: The function layout of industrial buildings should accord with contemporary material culture demands so as to conduct the 
systematic layout. The function layouts of industrial buildings at the end of last century in our country are generally divided into storage space, processing workshop, transfer space, transport and storage space and collective living space for workmen. Firstly, classrify industrial buildings according to layering of the industrial buildings and make key protection with a little of maintenance development to those belonging to industrial heritages; conduct selective protection and integrated development and reconstruction to those belonging to common industrial buildings (including rebuilding and reinforcement of buildings and the integrated layout transformation of building groups etc); conduct the protective dismantlement to those belonging to the waste and dangerous industrial buildings. Second, conduct the position of external environment and development modes to determine whether it is of economic interest or public welfare. Finally conduct the position of subdivision of building function space such as the development mode of common buildings with a combination of economic benefit and public welfare.

Beijing 798 is a creative industry park developed earlier in China which was later built into an industrial park. During the early period, due to the low plant rents, many artists frequently gathered here. With the continuous deepening of state policies, this region is gradually developed into a development mode integrating artistic creation, artwork development, artwork sales and exhibition. The building group space under this situation will mainly be determined according to the service condition mentioned above. Small-scale industrial buildings here act as creation studios while the large-scale ones (such as workshops and plants) mainly are used for exhibition and conferences. (as shown in Fig. 3, Fig. 4).

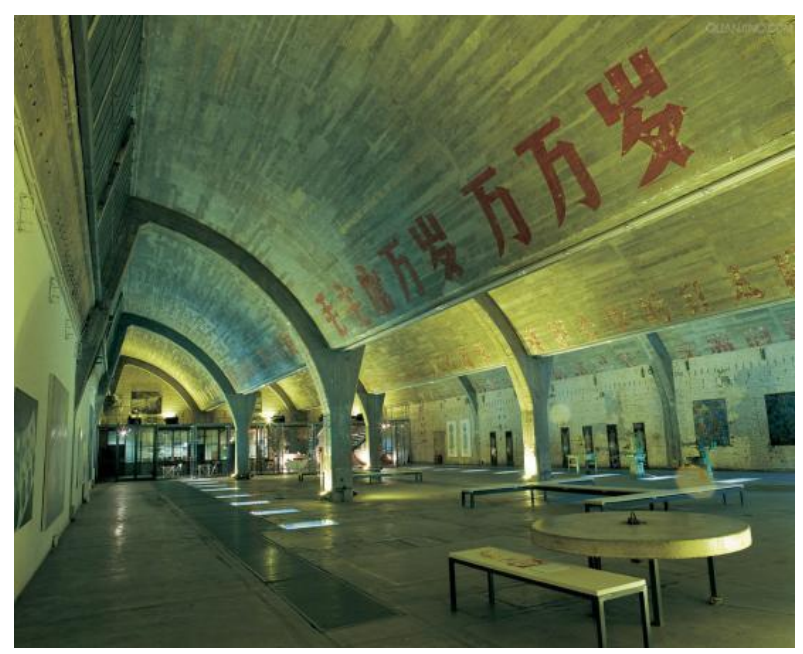

Fig. 3. The artwork exhibition halls transformed from workshop (www. p5w. net)

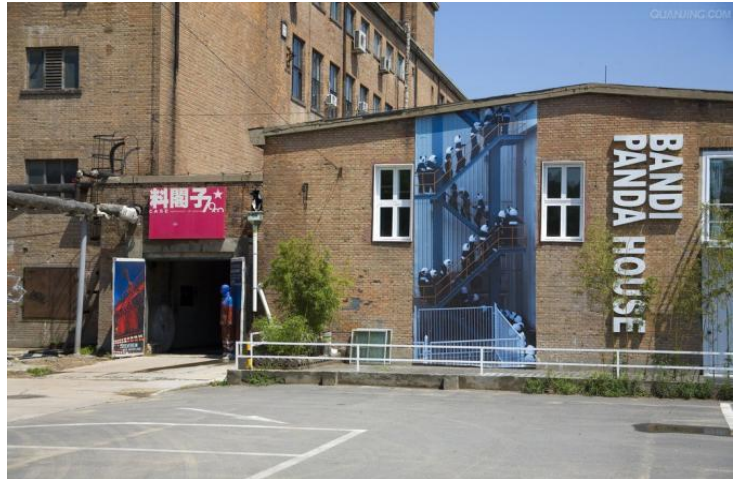

Fig. 4. Small-scale industrial building acting as artistic studio (www. p5w. net)

2) Formal "renascence" of industrial buildings: The forms of industrial buildings mainly are manifested by the materials. The original industrial buildings mainly adopted red bricks therefore many of the early industrial buildings dated back to the end of last century that we can see at home and abroad adopted red bricks as main material. For the "renascence" of the forms of original industrial buildings, first, we should maintain the sensory perception of the people on buildings and adopt new technologies or new materials on that basis. Whether the internal decoration of building or the reinforcement of building structures or the enrichment of building façade, they all should ensure the buildings to become more modern with no lack of its previous building features. (as shown in Fig. 5, Fig. 6)

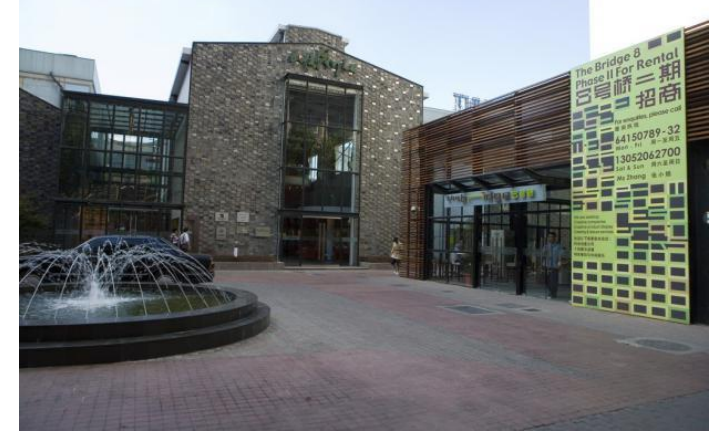

Fig. 5. New material combination of the industrial buildings in Shanghai industry park

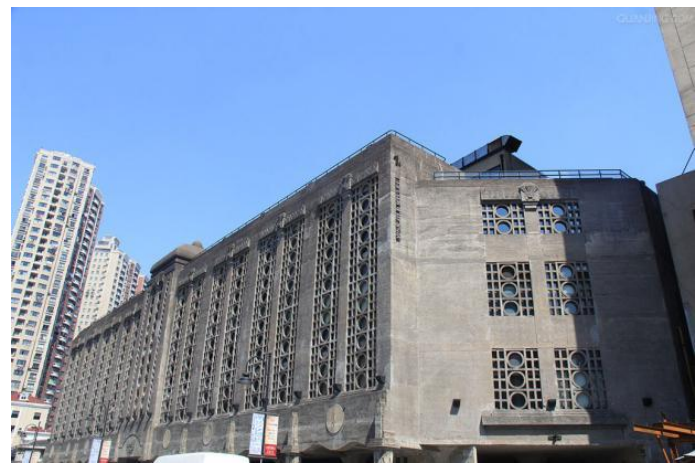

Fig. 6. Transformation of Shanghai 1933 Old Millfun 
3) Spatial production "renascence" of industrial buildings: Spatial production is a mode defined for spatial economic development. The innovation of space production of industrial buildings should be derived from the integrated environment around buildings and the spatial development planning. The original space production mode of industrial buildings belongs to a linear layout like a flow line of a product where the parts manufacturing and assembly are conducted according to the fixed procedures to finally form a complete product. However, in contemporary era, significant changes have occurred on the economic mode of space production which is transformed into the nonlinear space production mode from the original linear production mode, aiming to develop toward a multiple and ecological system for the space production and form a spatial economic development mode with self-satisfaction and self-renewing in a regional space.

\section{CONCLUSION}

Relying on the policy support for creative industry development and the background of innovation and transformation of economic development to drive the innovation and transformation of industrial buildings, that is, the "renascence" of industrial buildings consists of the "renascence" of function, form and the spatial production of industrial buildings under the major background of creative industry. regroup the three "renascence" modes (according to the social environment of industrial buildings and other factors) so as to achieve the effective promotion of the capacities of spatial economic production, cultural development and inheritance, resident living demand and the urban selfrenewing of the entire region. Most of undeveloped cities may borrow the development mode of this region and then promote the "renascence" of original industrial buildings according to the industrial building features in the region of their own.

\section{REFERENCES}

[1] Zhang Qiang, Status, Layout and Development Countermeasure of Urban Culture Creative Industry in China[J]. Progress in Geography, 2013.Vol32. No8.P1127-1136

[2] Howkins,J.The Creative Economy:How People Make Money From Ideas[M].Allen Lane/Penguin Press,2001.

[3] UNCTAD.Creative Economy Report 2008 [R].Geneva:UNCTAD,2008.

[4] Mommaas, H.Spaces of Culture and Economy:Mapping the CulturalCreative.

[5] Cluster Landscape [M] . In Kong and O' Connor,2009:45-60.

[6] Shen Lihong, Cen Yu, Yu Liying, Study on the Recycle of Industrial Building Heritages[J]. Ecological Economy, 2008.05. P144-146.

[7] Zhuang Jiandi. Study on Several Problems on Recycle of Original Industrial Buildings[D]. Tsinghua University, 2004.

[8] Wang Xiyun. Study on the Transformation between "ResourceProduct" of Industrial Heritage Tourism[D]. Nanjing Normal University, 2007.

[9] Liu Boying. Review on the Protection and Development of Industrial Building Heritages[J]. Architectural Journal. 2012.1. P12-17. 